\title{
Extension of the CJP model to mixed mode I and mode II
}

\author{
C. J. Christopher, G. Laboviciute, M. N. James \\ University of Plymouth, Drake Circus, Plymouth PLA 8AA, UK \\ mjames@plymouth.ac.uk

\section{E. A. Patterson} \\ University of Liverpool, Brownlow Hill, Liverpool, L69 3GH, UK
}

\begin{abstract}
The present authors have previously proposed a novel 'plastic inclusion' approach for dealing with the local plasticity which occurs at the tip of a growing fatigue crack. This meso-scale model provides a modified set of crack tip stress intensity factors that include the magnitude of plastic wake-induced crack tip shielding and which have the potential to help resolve some long-standing controversies associated with plasticity-induced closure. The present work extends the CJP model to deal with the case of mixed Mode I and Mode II loading and thus opens up enhanced possibilities for testing it on inclined cracks in metallic specimens. This extension requires the addition of only one new force parameter to the model, i.e. an anti-symmetric shear force on either side of the crack.
\end{abstract}

KEYWORDS. Mixed mode fatigue; CJP crack tip stress model; plastic inclusion; crack tip shielding.

\section{INTRODUCTION}

7 he present authors have previously proposed a novel 'plastic inclusion' approach for dealing with the local plasticity which occurs at the tip of a growing fatigue crack [1]. Localised plasticity arises from crack growth mechanisms and essentially blunts the crack, creates a reversed cyclic plastic zone, and induces shear along the crack flanks, along with the possible generation of wake contact stresses which act on the applied elastic stress field at the boundary of the elastic-plastic enclave surrounding the crack. The outcome of this meso-scale model is a modified set of crack tip stress intensity factors that include the magnitude of plastic wake-induced crack tip shielding and which have the potential to help resolve some long-standing controversies associated with plasticity-induced closure. A full-field approach has been developed for stress using photoelasticity and also for displacement using digital image correlation. This model has been termed the CJP model by the authors, and is independent of the mechanisms of plastic deformation and is therefore potentially applicable to a variety of materials. The definition of the forces on the crack allows roughness-induced closure to also be accounted for in the calculated stress intensity factors. The model can also be used to mathematically explore the effect on shape of the crack tip stress field of changes in magnitude of the various parameters; for, example, the effect of variation in magnitude of increasing positive or negative T-stress on crack tip fringe patterns.

Under Mode I loading, the new model uses four parameters to characterize the stress fields generated by the forces in Fig. 1; an opening mode stress intensity factor $K_{\mathrm{F}}$, the shear stress intensity factor $\mathrm{K}_{\mathrm{S}}$, the retardation stress intensity factor $K_{R}$, and the T-stress. In applications involving the DIC technique, stress intensity factors in the new four-parameter model can be solved directly from measured displacement fields using Muskhelishvili's potential functions. 
Forces on plastic field

Forces on elastic field

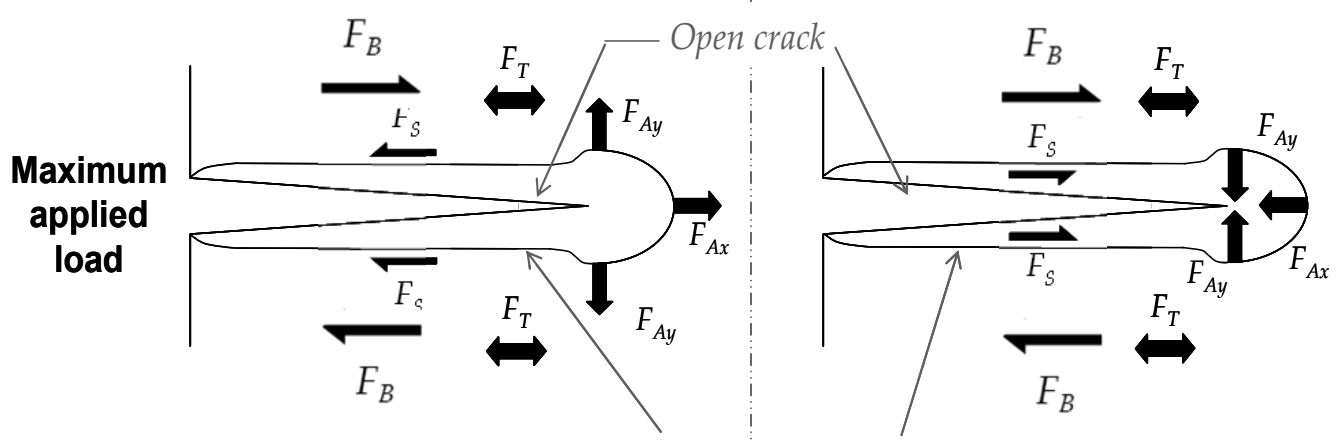

Notational boundary of plastically deformed material

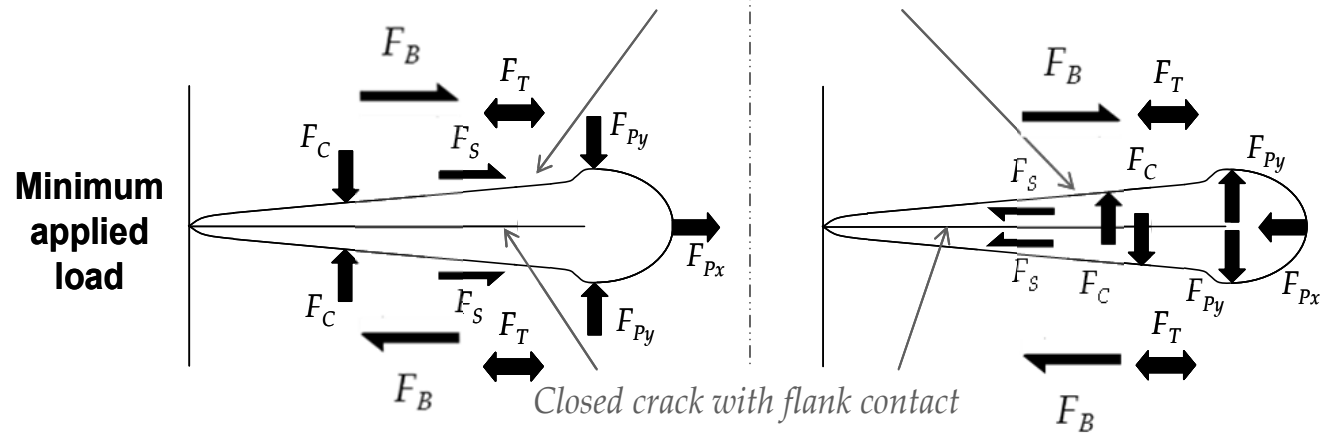

Figure 1: Schematic idealisations of forces acting at the interface of the plastic enclave and the surrounding elastic material, where $F_{A}$ is the Mode I applied force generating the crack tip stress field usually characterized by $\mathrm{K}_{\mathrm{I}}, \mathrm{F}_{\mathrm{B}}$ is the additional applied force induced by Mode II loading, $\mathrm{F}_{\mathrm{T}}$ represents the force due to the $\mathrm{T}$-stress shown in this example as positive, $\mathrm{F}_{\mathrm{S}}$ is the interfacial shear force between the elastic and plastic zones, $F_{C}$ and $F_{P}$ together create the shielding effect. $F_{P}$ is the force generated by the constraint of compatibility on the plastically deformed material and $\mathrm{F}_{\mathrm{C}}$ is the contact force between the flanks of the crack generated by the interference of the plastic zones along the flanks [1].

The present work extends the CJP model to deal with the case of mixed Mode I and Mode II loading and thus opens up enhanced possibilities for testing it on inclined cracks in metallic specimens. This extension requires the addition of only one new force parameter to the model, shown as $\mathrm{F}_{\mathrm{B}}$ in Fig. 1, i.e. an anti-symmetric shear force on either side of the crack.

\section{THE CJP MODEL UNDER BIAXIAL (MODE I AND MODE II) LOADING}

he CJP Model [1] is defined as:

$\mathcal{L}\left|\sigma_{\mathrm{y}}-\sigma_{\mathrm{x}}+2 \mathrm{i} \sigma_{\mathrm{xy}}\right|=\mathrm{A} z^{-\frac{1}{2}}+\mathrm{Bz}{ }^{-\frac{3}{2}} \overline{\mathrm{z}}+\mathrm{C} z^{0}+\mathrm{D} z^{-\frac{1}{2}} \ln (\mathrm{z})+\mathrm{E} z^{-\frac{3}{2}} \overline{\mathrm{z}} \ln (\mathrm{z})$

The extension to the model was obtained by making the coefficients $\mathrm{A}$ and $\mathrm{B}$ complex and making the assumptions $A=A_{r}+i 3 B_{i}, B=B_{r}+i B_{i}, D+E=0$.

$$
\left|\sigma_{\mathrm{y}}-\sigma_{\mathrm{x}}+2 \mathrm{i} \sigma_{\mathrm{xy}}\right|=\left(\mathrm{A}_{\mathrm{r}}+\mathrm{i} 3 \mathrm{~B}_{\mathrm{i}}\right) \mathrm{z}^{-\frac{1}{2}}+\left(\mathrm{B}_{\mathrm{r}}+\mathrm{iB}\right) \mathrm{z}^{-\frac{3}{2}} \overline{\mathrm{z}}+\mathrm{C} \mathrm{z}^{0}+\mathrm{D} \mathrm{z}^{-\frac{1}{2}} \ln (\mathrm{z})+\mathrm{E} \mathrm{z}^{-\frac{3}{2}} \overline{\mathrm{z}} \ln (\mathrm{z})
$$

The elastic stress fields near the crack tip are given by: 


$$
\begin{aligned}
\sigma_{\mathrm{y}}= & \frac{1}{2}\left(\mathrm{~A}_{\mathrm{r}}-4 \mathrm{~B}_{\mathrm{r}}-8 \mathrm{E}\right) \mathrm{r}^{-\frac{1}{2}} \cos \frac{\theta}{2}+\frac{1}{2} \mathrm{~B}_{\mathrm{r}} \mathrm{r}^{-\frac{1}{2}} \cos \frac{5 \theta}{2}+\frac{1}{2} \mathrm{~B}_{\mathrm{i}} \mathrm{r}^{-\frac{1}{2}}\left(\sin \frac{5 \theta}{2}-\sin \frac{\theta}{2}\right) \\
& +\frac{1}{2} \mathrm{Er}^{-\frac{1}{2}}\left[\ln (\mathrm{r})\left(\cos \frac{5 \theta}{2}-5 \cos \frac{\theta}{2}\right)+\theta\left(\sin \frac{5 \theta}{2}-5 \sin \frac{\theta}{2}\right)\right]+\mathrm{O}\left(\mathrm{r}^{\frac{1}{2}}\right) \\
\sigma_{\mathrm{x}}= & -\frac{1}{2}\left(\mathrm{~A}_{\mathrm{r}}+4 \mathrm{~B}_{\mathrm{r}}+8 \mathrm{E}\right) \mathrm{r}^{-\frac{1}{2}} \cos \frac{\theta}{2}-\frac{1}{2} \mathrm{~B}_{\mathrm{r}} \mathrm{r}^{-\frac{1}{2}} \cos \frac{5 \theta}{2}-\frac{1}{2} \mathrm{~B}_{\mathrm{i}} \mathrm{r}^{-\frac{1}{2}}\left(\sin \frac{5 \theta}{2}+7 \sin \frac{\theta}{2}\right) \\
& -\frac{1}{2} \mathrm{Er}^{-\frac{1}{2}}\left[\ln (\mathrm{r})\left(\cos \frac{5 \theta}{2}+3 \cos \frac{\theta}{2}\right)+\theta\left(\sin \frac{5 \theta}{2}+3 \sin \frac{\theta}{2}\right)\right]-\mathrm{C}+\mathrm{O}\left(\mathrm{r}^{\frac{1}{2}}\right) \\
\sigma_{\mathrm{xy}}= & -\frac{1}{2} \mathrm{r}^{-\frac{1}{2}}\left(\mathrm{~A} \mathrm{r} \sin \frac{\theta}{2}+\mathrm{B}_{\mathrm{r}} \sin \frac{5 \theta}{2}\right)+\frac{1}{2} \mathrm{~B}_{\mathrm{i}} \mathrm{r}^{-\frac{1}{2}}\left(\cos \frac{5 \theta}{2}+3 \cos \frac{\theta}{2}\right) \\
& -\mathrm{Er}^{-\frac{1}{2}} \sin \theta\left[\ln (\mathrm{r}) \cos \frac{3 \theta}{2}+\theta \sin \frac{3 \theta}{2}\right]+\mathrm{O}\left(\mathrm{r}^{\frac{1}{2}}\right)
\end{aligned}
$$

$\mathrm{K}_{\mathrm{F}}$ is defined from the asymptotic limit of $\sigma_{\mathrm{y}}$ as $\mathrm{x} \rightarrow+0$, along $\mathrm{y}=0$, i.e. towards the crack tip from the front along the crack line:

$$
\mathrm{K}_{\mathrm{F}}=\lim _{\mathrm{r} \rightarrow 0}\left[\sqrt{2 \pi \mathrm{r}}\left(\sigma_{\mathrm{y}}+2 \mathrm{Er} \mathrm{r}^{-\frac{1}{2}} \ln (\mathrm{r})\right)\right]=\sqrt{\frac{\pi}{2}}\left(\mathrm{~A}_{\mathrm{r}}-3 \mathrm{~B}_{\mathrm{r}}-8 \mathrm{E}\right)
$$

$\mathrm{K}_{\mathrm{R}}$ was obtained by evaluating $\sigma_{\mathrm{x}}$ in the limit as $\mathrm{x} \rightarrow-0$, along $\mathrm{y}=0$, i.e. towards the crack tip from behind along the crack flank:

$$
\mathrm{K}_{\mathrm{R}}=\lim _{\mathrm{r} \rightarrow 0}\left[\sqrt{2 \pi \mathrm{r}} \sigma_{\mathrm{x}}\right]=-4 \sqrt{\frac{\pi}{2}}\left(2 \mathrm{~B}_{\mathrm{i}}+\mathrm{E} \pi\right)
$$

$\mathrm{K}_{\mathrm{s}}$ is derived from the asymptotic limit of $\sigma_{\mathrm{xy}}$ as $\mathrm{x} \rightarrow-0$, along $\mathrm{y}=0$, i.e. towards the crack tip from behind along the crack flank:

$$
\mathrm{K}_{\mathrm{S}}=\lim _{\mathrm{r} \rightarrow 0}\left[\sqrt{2 \pi \mathrm{r}} \sigma_{\mathrm{xy}}\right]=\mp \sqrt{\frac{\pi}{2}}\left(\mathrm{~A}_{\mathrm{r}}+\mathrm{B}_{\mathrm{r}}\right)
$$

The +ve sign indicates $\mathrm{y}>0$, and a - ve sign that $\mathrm{y}<0$.

The quantity $\mathrm{K}_{\mathrm{II}}$ characterizes mode II loading, and is derived from the asymptotic limit of $\sigma_{\mathrm{xy}}$ as $\mathrm{x} \rightarrow-0$, along $\mathrm{y}=0$, i.e. towards the crack tip from the front along the crack line:

$$
\mathrm{K}_{\mathrm{II}}=\lim _{\mathrm{r} \rightarrow 0}\left[\sqrt{2 \pi \mathrm{r}} \sigma_{\mathrm{xy}}\right]=2 \sqrt{2 \pi} \mathrm{B}_{\mathrm{i}}
$$

T-stress is the transverse stress which is added to $\sigma_{\mathrm{x}}$ as a constant term and is given by

$$
\mathrm{T}=-\mathrm{C}
$$

The new five-parameter model can be solved for displacement fields: 


$$
\begin{aligned}
2 \mu\left(\mathrm{u}_{\mathrm{x}}+\mathrm{iu}_{\mathrm{y}}\right)= & \kappa\left(-2\left(\mathrm{~B}_{\mathrm{r}}+\mathrm{iB} \mathrm{B}_{\mathrm{i}}\right) \mathrm{z}^{\frac{1}{2}}-2 \mathrm{E} \mathrm{z}^{\frac{1}{2}} \ln (\mathrm{z})-\frac{\mathrm{C}}{4} \mathrm{z}\right) \\
& -\mathrm{z}\left(-\left(\mathrm{B}_{\mathrm{r}}+\mathrm{i} \mathrm{B}_{\mathrm{i}}+2 \mathrm{E}\right) \overline{\mathrm{z}}^{-\frac{1}{2}}-\mathrm{E} \overline{\mathrm{z}}^{-\frac{1}{2}} \frac{\mathrm{ln}(\mathrm{z})}{\ln }-\frac{\mathrm{C}}{4}\right) \\
& -\left(\left(\mathrm{A}_{\mathrm{r}}+\mathrm{i} 3 \mathrm{~B}_{\mathrm{i}}\right) \overline{\mathrm{z}}^{\frac{1}{2}}+\mathrm{D} \overline{\mathrm{z}}^{\frac{1}{2}} \overline{\ln (\mathrm{z})}-2 \mathrm{D} \overline{\mathrm{z}}^{\frac{1}{2}}+\frac{\mathrm{C}}{2} \overline{\mathrm{z}}\right)
\end{aligned}
$$

Where $\mathrm{u}_{\mathrm{x}}$ and $\mathrm{u}_{\mathrm{y}}$ are the horizontal and vertical displacements respectively, $\mu=\frac{\mathrm{E}}{2(1+v)} ; \kappa=3-4 v$ (plane strain) or $\kappa=\frac{3-v}{1+v}$ (plane stress). $\mathrm{u}_{\mathrm{x}}$ and $\mathrm{u}_{\mathrm{y}}$ are shown explicitly below with the assumption $\mathrm{D}+\mathrm{E}=0$.

$$
\begin{aligned}
2 \mu \mathrm{u}_{\mathrm{x}}= & \mathrm{r}^{\frac{1}{2}}\left(-\mathrm{A}_{\mathrm{r}}-2 \mathrm{~B}_{\mathrm{r}} \kappa-2 \mathrm{E}\right) \cos \frac{\theta}{2}+\mathrm{r}^{\frac{1}{2}}\left(2 \mathrm{~B}_{\mathrm{i}} \kappa-3 \mathrm{~B}_{\mathrm{i}}\right) \sin \frac{\theta}{2}+\mathrm{r}^{\frac{1}{2}}\left(\mathrm{~B}_{\mathrm{r}}+2 \mathrm{E}\right) \cos \frac{3 \theta}{2} \\
& -\mathrm{r}^{\frac{1}{2}} \mathrm{~B}_{\mathrm{i}} \sin \frac{3 \theta}{2}+\mathrm{r}^{\frac{1}{2}} \mathrm{E}\left[\ln (\mathrm{r})\left(\cos \frac{3 \theta}{2}+(1-2 \kappa) \cos \frac{\theta}{2}\right)+\theta\left(\sin \frac{3 \theta}{2}+(1+2 \kappa) \sin \frac{\theta}{2}\right)\right] \\
& -\frac{\mathrm{C}}{4} \mathrm{r}(1+\kappa) \cos \theta \\
2 \mu \mathrm{u}_{\mathrm{y}}= & \mathrm{r}^{\frac{1}{2}}\left(-2 \mathrm{~B}_{\mathrm{i}} \kappa-3 \mathrm{~B}_{\mathrm{i}}\right) \cos \frac{\theta}{2}+\mathrm{r}^{\frac{1}{2}}\left(\mathrm{~A}_{\mathrm{r}}-2 \mathrm{~B}_{\mathrm{r}} \kappa+2 \mathrm{E}\right) \sin \frac{\theta}{2}+\mathrm{r}^{\frac{1}{2}}\left(\mathrm{~B}_{\mathrm{r}}+2 \mathrm{E}\right) \sin \frac{3 \theta}{2} \\
& +\mathrm{r}^{\frac{1}{2}} \mathrm{~B}_{\mathrm{i}} \cos \frac{3 \theta}{2}+\mathrm{r}^{\frac{1}{2}} \mathrm{E}\left[\ln (\mathrm{r})\left(\sin \frac{3 \theta}{2}-(1+2 \kappa) \sin \frac{\theta}{2}\right)-\theta\left(\cos \frac{3 \theta}{2}+(1+2 \kappa) \cos \frac{\theta}{2}\right)\right] \\
& +\frac{\mathrm{C}}{4} \mathrm{r}(3-\kappa) \sin \theta
\end{aligned}
$$

\section{APPLICATION OF THE MODEL TO MIXED MODE CRACK GROWTH}

7 hus far, the model has been tested against limited data obtained from an inclined crack in a 2mm thick 2024-T6 aluminium CT specimen with non-standard dimensions, which is shown in Fig. 2. A jeweller's saw with blade thickness of $0.15 \mathrm{~mm}$ was used to extend the notch tip into a $45^{\circ}$ slit some $5 \mathrm{~mm}$ long, which is schematically shown in Fig. 2. A fatigue crack some $2 \mathrm{~mm}$ long was then grown in Mode I collinear with this slit. This was achieved by starting with a larger dimension CT specimen with additional loading holes in a similar fashion to the disk-shaped compact specimen described by Ding et al [2]. The specimen was then machined to final dimensions and approximately 100 cycles of loading was applied in the usual orientation, so as to put the fatigue crack under a combination of mixed Mode I and Mode II loading. The applied load ratio was $R=0.1$ and the peak load was $1.2 \mathrm{kN}$. A Dantec digital image correlation (DIC) system operating in $2 \mathrm{D}$ mode was used to measure the crack tip displacement field and to compare the predictions of the CJP model with the measured strain field data. A facet size of 17 pixels with a centre-line pitch of 17 pixels was used with a scale of 107 pixels per millimetre.

It is acknowledged that this method of cracking is not optimum, as it produces a Mode I plastic wake, rather than one that reflects mixed mode loading. However, the technique gives data for a mixed mode crack tip strain field and a Mode I crack wake and this is not dissimilar to the data acquired by many other workers, e.g. [2]. Attention will be given in the immediate future to testing cracks of various inclinations, i.e. various mode-mixity ratios, which have been developed under true mixed mode loading, as well as under Mode I loading.

Fig. 3 presents a comparison between the measured $x$ and $y$ components of the crack tip displacement and those predicted by the 5-parameter CJP mixed mode model, whilst Fig. 4 show typical stress intensity data measured through a loading half cycle. In Fig. 4 the stress intensity factors are all defined with respect to the local crack plane, i.e. $K_{F}$ and $K_{I I}$ values are defined as respectively being perpendicular to, and parallel with, the plane of the inclined crack. The stress intensity factors can be fairly easily re-defined using simple geometry, with Cartesian coordinates defined in terms of the load line 
and the plane of the original notch in the CT specimen, e.g. $K_{F}=\left(K_{F}+K_{I I}\right) / \sqrt{ } 2$ and $K_{I I}=\left(K_{f} K_{I I}\right) / \sqrt{ } 2$ (or the negative of this, depending on how the force directions were chosen). However, the belief of the present authors is that it is more useful to define stress intensity factors in terms of the local crack plane, because crack growth rate is governed by these local conditions.

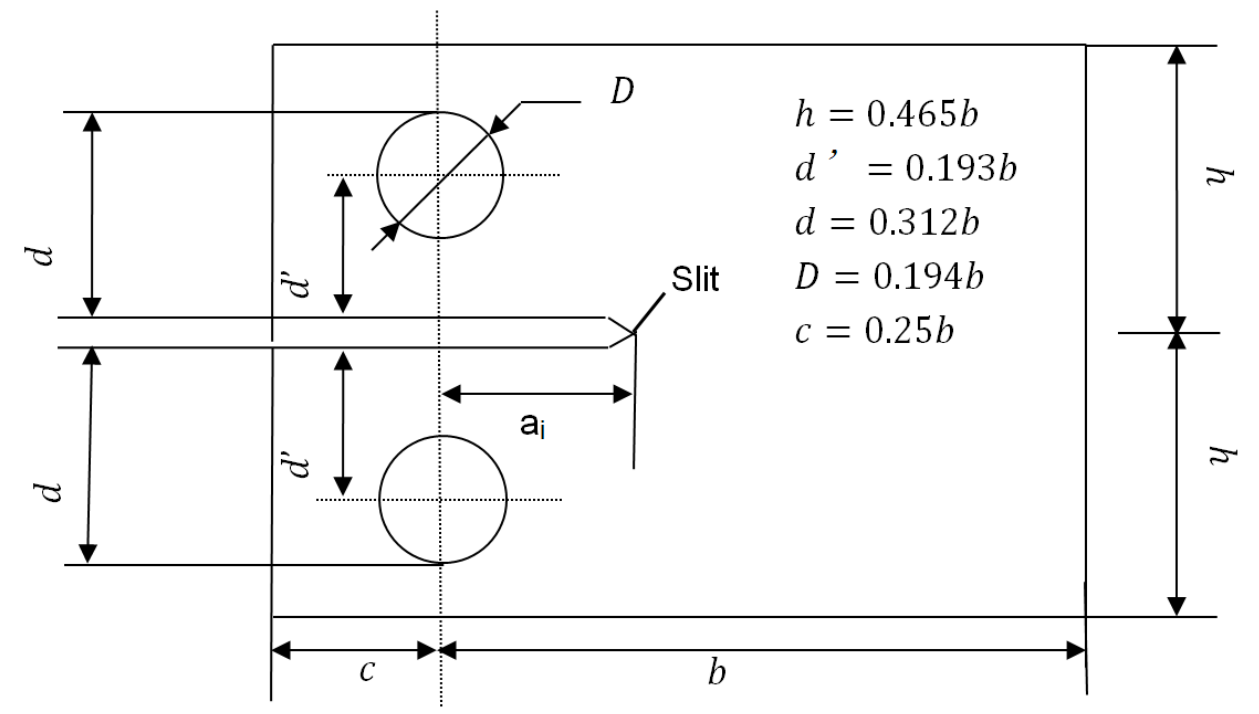

Figure 2: Geometry and dimensions (in millimetres) of the polycarbonate compact tension (CT) specimens used in this work. Note that the notch length (equal to the initial crack length) $a_{i}=20 \mathrm{~mm}$ and the width $b=W=72 \mathrm{~mm}$ are defined from the centreline of the holes.

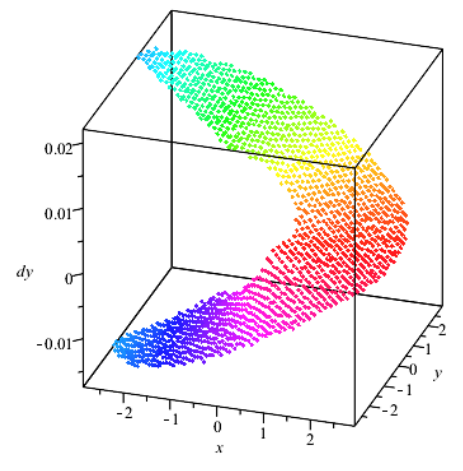

a) DIC: $y$-displacement

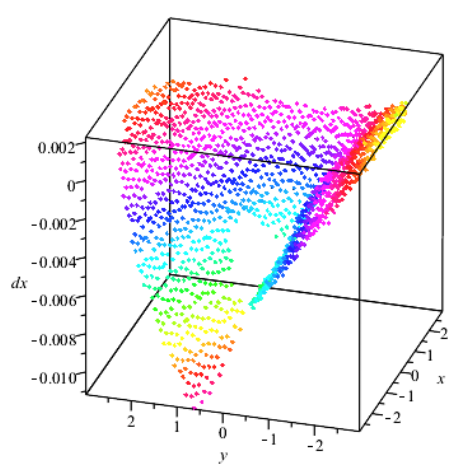

c) DIC: $x$-displacement

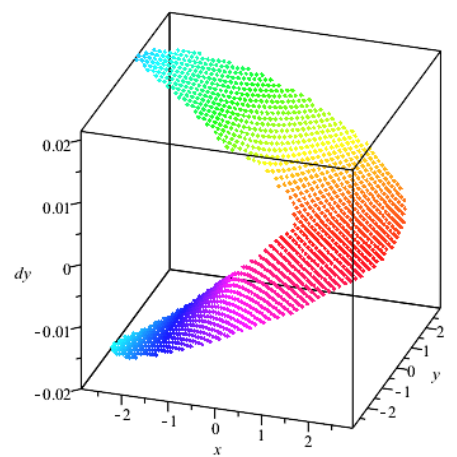

b) CJP model: $y$ -

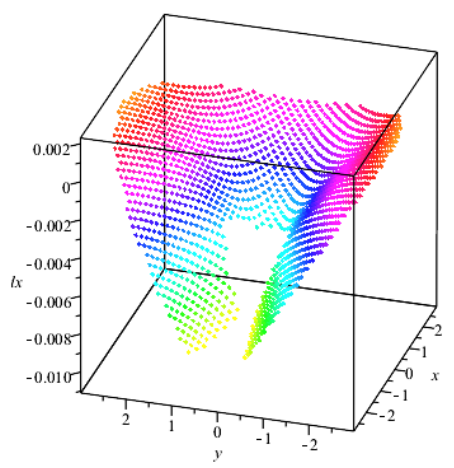

d) CJP model: $x$ -

Figure 3: Comparison between DIC and CJP model predictions of the $x$ and $y$-displacement fields at the tip of a crack under mixed mode fatigue loading. 


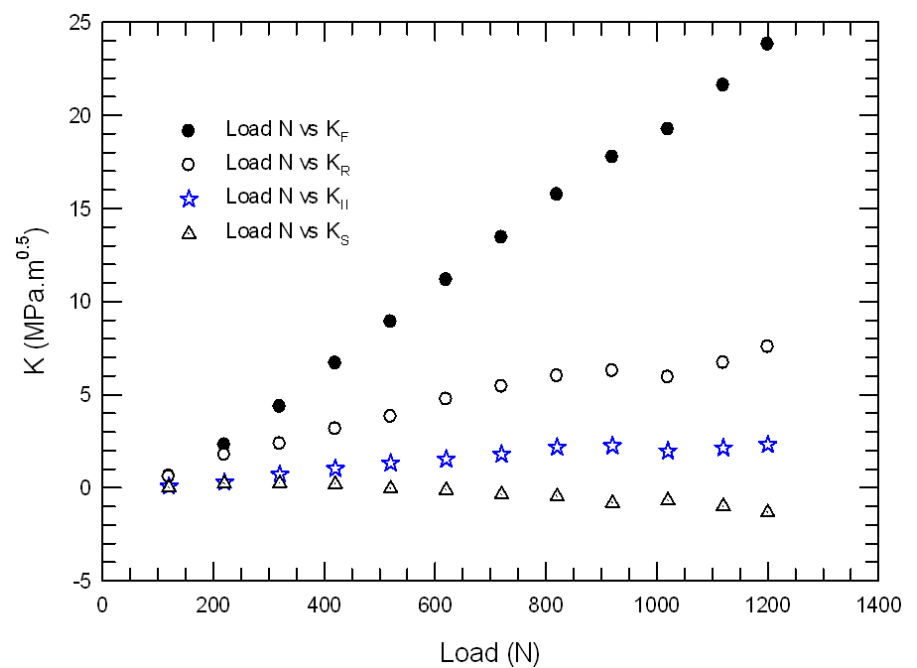

Figure 4: Stress intensity values given by the mixed-mode CJP equation, with $\mathrm{K}_{\mathrm{F}}$ defined perpendicular to the $45^{\circ}$ slant crack and $\mathrm{K}_{\mathrm{II}}$ defined parallel with the slant crack in the CT specimen.

\section{CONCLUSIONS}

The CJP model has been extended to deal with fatigue cracking under mixed mode I and II conditions, by incorporating an additional anti-symmetric horizontal shear force into the analysis. The model appears able to accurately predict the $x$ and $y$-displacement fields ahead of the tip of a crack under mixed mode loading. Further work is on-going to explore the accuracy of the predictions, the values of the mixed mode stress intensity factors and their use in predicting fatigue crack growth rates.

\section{REFERENCES}

[1] James, M.N., Christopher, C.J., Lu, Y. and Patterson, E.A., Local crack plasticity and its influences on the global elastic stress field. Int. J. Fatigue, 46 (2013) 4-15.

[2] Ding, F, Zhao, T. and Jiang, Y., A study of fatigue crack growth with changing load direction. Engng Fract. Mech., 74 (2007) 2014-2029. 